\title{
Probe into the training mode of clinical nurse specialists in China
}

\author{
Yukun Zhang and Yan Song ${ }^{a}$ \\ Beihua university, 132013, jilin, China
}

\begin{abstract}
Overview of the clinical nurse specialist development history, current situation and training mode, and according to the current situation of the development of clinical nursing specialist in China, proposed the convergence of clinical nurse specialist and master of nursing specialist training, and put forward the new training mode of the "four cards and one" ,and analyzes the feasibility and difficulties.
\end{abstract}

\section{Introduction}

In recent years, with the rapid development of medical science and technology and the continuous improvement of people's health needs, the training of highly qualified specialists has become the trend of the development of nursing science in the new era. Clinical nursing specialist(CNS), as an important part of advanced nurse practice(ANP), plays an important role in the development of nursing science. It can not only effectively promote the development of nursing research and teaching, but also reduce the gap between nursing research and practice, thus to improve the quality of care and reduce the cost of nursing [1]. According to the research report, China began to study the CNS in 2001 [2], and in 2010, the training of Master of nursing specialist(MNS) was started, although some progress has been made in the development of CNS and MNS in recent years, it has not formed a unified, sound training mode yet, it is still in the exploratory stage. How to explore the CNS training model which conforms to the situation of our country is the urgent problem to be solved in the development of nursing specialty in our country [3].

\section{CNS development status in China}

\subsection{The definition of CNS}

In the United States,as early as 1910, nursing experts put forward to cultivate a higher level of nursing talents in certain diseases, and officially called clinical nursing specialist (CNS) in the 1960s[4]. At present, the international concept of universal recognition of the CNS is the definition of the American Nursing Association (ANA): CNS is a registered nurse with the master or doctoral degree, with rich clinical experience and a high level of nursing skills and is an expert in a particular field of clinical knowledge [5].

\footnotetext{
${ }^{\mathrm{a} C}$ Corresponding author: Yan Song, 1293625334@qq.com
} 


\subsection{Development status of CNS in China}

In 1996, Hong Deng first introduced the concept of clinical nursing experts in the country, and introduced the development of foreign CNS[6]. Our country began the training work in 2001[2]. Zhongshan University nursing college, University of Hongkong and the Hongkong Institute of stoma co founded the first fistula qualification certificate for school in 2001, training the first batch by the international certification of CNS in China[7], Sir Run Run Shaw Hospital Affiliated to Medical College of Zhejiang University Cultured the diabetes advanced practice nurses and wound / stoma advanced practice nurses[8]. In recent years, Beijing, Shanghai, Hangzhou and other places have begun to carry out CNS training in critical care, stoma or wound and other fields, although many areas have a certain foundation in training, the cultivation of the CNS is still in the embryonic stage. Over the past ten years, the literature on CNS has been increasing year by year, but mainly on the CNS training system, training direction, some studies on the core competence and business ability, the merger of CNS training mode and MNS system has not yet been reported in the literature. And in the development of nursing specialty, especially to the development of diabetes nurse specialist [9], nephropathy nursing experts [10], pressure sores nursing experts [11], operating room nursing experts [12], developed quickly. And cancer care, family peritoneal dialysis, coronary heart disease and other 20 professional nursing experts in the field of consultation with the patient has been in Shanghai First People's Hospital [13].

\section{Preliminary exploration of the CNS training model in China}

\subsection{Preliminary exploration of CNS}

Reading the literature found that domestic experts mainly have "specialized nurse" and "clinical nurse specialist" two kinds of translation on CNS. This is mainly due to the ambiguity caused by differences in the comprehension and translation, Only the concept of the two and the role of functional orientation,can we gradually achieve with the international standards[3]. Xiaojie Wang and etc[14] researched on the concept of specialist nurses and clinical nursing experts in our country, pointing that the specialized nurse should be referred to those who experienced some specialized training system and obtain the professional qualification certificate of nurses.Xiaojie Wang expert interviews and letters of inquiry results show: $75.6 \%$ of the experts agree the CNS translated into clinical nurse specialists, and 36 percent of nursing experts think CNS of personnel training should be nursing postgraduates [15].Feng Li and others [16] think, through the training of nursing graduate students to cultivate nursing expert talent is the inevitable development of nursing in specialist. Wenwen Zhang [17] by means of Delphi to 33 experts for consultation, and $88.9 \%$ of the experts believe that nursing graduate students will be the senior practitioner of nursing after graduation.

\subsection{The assumption of "four certificates and one"}

With the vigorous development of higher nursing education in recent years, Study of nursing postgraduate education scale is also expanding, by the end of 2015, there had 86 colleges and universities in our country with the master's degree in nursing science. On the one hand, the high level of nursing personnel is increasing, on the other hand, the development of specialized nursing science is also urgent for us to develop CNS as soon as possible. Under this background, The author puts forward the idea of "four certificates and one" for the training of clinical nursing specialist and master of nursing science, namely after graduation, we will acquire CNS certificate, nurse standardized training certificate, master's degree and professional master's degree certificate. Putting the CNS training and professional master's training combined closely. At the end of 2015, National Ministry of Health issued the outline of the standardized training program for nurses, the middle of which did not involve whether to continue compliance training content for professional master graduate students after graduation, this is undoubtedly not fair for the professional master's graduate students, because 
during the period of school they had been completed at least two years practice rotary. The implementation of the "four cards and one" can not only promote the development of nursing graduate education, but also speed up the pace of the development of CNS.

\subsection{Feasibility of CNS and MNS integration}

\subsubsection{Comparison of current situation of cultivation}

The cultivation of CNS and MNS has relevance in attribute[18]. The training target localization of CNS and MNS are of high level, applied and professional nursing talents, which showed that the master of nursing and clinical nursing experts have consistency in nature. In addition, By comparison, it is found that CNS and MNS have great similarity[19] (see Table 1) in terms of enrollment standard, training mode and core competence, which provide the possibility and feasibility for the combination of the two.

Table 1. Comparison of CNS and MNS in cultivation

\section{Project Enrollment standard Cultivation mode $\quad$ Core ability $\quad$ Cultivation direction}

Bachelor degree; Or School training; Educational ability; Emergency critical equivalent; Through hospital training; scientific research care; nursing nurse qualification hospital school ability; clinical skill; management; exam;2-3 academic joint training. nursing management; surgical nursing; year. thinking ability; communication ability. pediatric nursing;

elderly care; psychiatric care, etc.
College degree or above; $3-5$ years

CNS

\section{working experience;} intermediate title; registered nurses; have certain scientific research ability.
Hospital training; hospital school joint training; joint training of hospital.

Clinical ability;
scientific research
ability leadership
ability; cooperation
ability; nursing
consultation,etc.

Diabetes care; operation room nursing;ICU nursing; emergency care; wound / stoma care, etc.

\subsubsection{The connect situation of professional degree and professional qualification of master degree in China}

In July 2011, Shanghai Municipal Education Commission, Shanghai Municipal Health Bureau jointly promulgated the Shanghai municipal hospital standardized training of physicians and clinical medicine master professional degree education convergence reform measures for implementation, began a clinical hospital standardized training of physicians and clinical graduate students education merger of pilot work [20]. The professional degree graduate students after graduation can achieve 
"four cards" (practitioner qualification certificate, standardized resident training certificate, Graduate Diploma, professional master degree certificate), so as to realize the organic combination of vocational qualification training ( The standardized training of resident physicians) and the organic combination of master's degree in clinical medicine. In addition, the professional of the convergence of master professional degree and professional qualifications, such as Master of architecture and registered architects[21]; Master of accounting and corresponding professional qualifications of the convergence, etc. The organic connection of other major also provides reference for the combination of nursing master's degree and clinical nursing specialist. Therefore, the implementation of CNS and MNS combined with the "four cards and one" is feasible, also is the inevitable trend of the development of nursing specialist in China.

\section{Analysis of difficulties in the connection between CNS and MNS}

\subsection{The practical ability of nursing postgraduates' training needs to be improved}

Whether MNS and CNS can achieve convergence, the key lies in the quality of their own as well as social recognition. As the MNS education in our country is just at the beginning stage, the lack of a unified, specific training programs, coupled with limited staff and other reasons, China's MNS can not be very good to highlight the connotation of its "advanced practice nurse". Therefore, we need to strengthen and improve the training system of MNS "hospital school joint training" and the "dual tutorial system".

\subsection{Gradually improve the CNS management system}

According to the actual situation of our country, we should define the working function of CNS, establish a reasonable salary system, establish an evaluation system, and the establishment of the system of CNS and MNS convergence. The most important is the establishment of the Certification Committee, the organization of the MNS assessment, qualification, etc.

\subsection{Establish pilot training institutions}

Strict training is the key to ensure the quality of the CNS, so we can choose some good development of nursing science, comprehensive strength of medical schools and their affiliated hospitals to establish CNS's main train station, so as to combine the CNS with MNS organically.

\subsection{CNS practice lack of legal protection}

Although we continue to explore the training mode of CNS in the last ten years, it still lacks legal protection.

\section{Conclusion}

In summary, CNS refers to the higher level of professional nursing knowledge and skills and rich clinical experience of experts. The cultivation of clinical nursing specialist in China is still in exploration stage, CNS and MNS for organic convergence can not only promote the development of higher nursing education but also promote the improvement of the quality of clinical nursing, to achieve a win-win results, so that the domestic nursing can gradually in line with the world. 


\section{References}

1. Profetto-McGrath J, Smith KB,etc. Worldviews Evid Based Nurs. Clinical nurse specialists' use of evidence in practice: A pilot study .J. 4(2),86-96(2007).

2. Wang BQ, Li J. Nursing research. Clinical nurse specialists development profile.( 16),1502-1503(2007).

3. Hou XY, Zhang HM, Li R. Nursing research. Clinical nurse specialists training mode.J.27( 11),961-963(2013).

4. Hunt JA. A dv Nurs. A specialist nurse: an identified professional role or a personal agenda.30(3),704-712(1999).

5. Mary MC, Maya JD. Nurse Clin of North Am. The role of the clinical nurse specialist in an adult congenital heart disease program.29(2),357-365(1994).

6. Pickergill F. Foreign medical: nursing in parts. Nurse practitioner and clinical nurse specialist is the trend of development .J.15( 1),35(1996).

7. Xu CJ, Wu QL. Journal of nursing management. ICU and colostomy specialist nurses present situation investigation and analysis.J. 6( 10),15-17(2006).

8. Feng JE, Hu HY, Lou QQ.Chinese Journal of nursing. A study on the role of advanced clinical nurse specialist.J.39( 2),115(2004).

9. Hu XR, Liu SQ, Mo YZ. Chinese Journal of nursing. Practice and experience in the establishment of diabetes specialist nursing training.J.42( 6),496-498(2007).

10. Li YJ, Zhang LY, Wang XL. Chinese Journal of nursing. Education of clinical nursing specialists of nephropathy.J.39(6),434-436(2004).

11. Xu WQ, Lou XH, Hao P. Nursing research. The effect of pressure ulcer nurse specialist on stage III severe pressure ulcer.J.20( 10),2790-2790(2006).

12. Zhao LH. Family nurse. Current situation and development trend of clinical nursing specialists in China. J.6( 21),1966-1967(2008).

13. Wei Hl, Li P, Fang F. Journal of nursing. Effect analysis and experience of nursing specialist outpatient clinic for 8 years.J.18( 9A),47-50(2011).

14. Wang XJ, Shen N. Journal of nursing management. Discussion on the concept of specialist nurses and clinical nursing specialists in our country.J.5( 12),25-26(2005).

15. Wang XJ, Shen N. Journal of nursing management. Cultivation and related problems of junior college nurses in China.J.6(12):8-11(2006).

16. Li F, Han J. Nursing research. Thoughts on the cultivation of master degree of clinical nursing.J.24( 3),266-267(2010).

17. Zhang WW, Wang AJ, Wang 1. Nursing research. Expert investigation and Research on the training program of master of nursing master's degree.J.26( 1),81-83(2012).

18. Guo J, Wang Y, Lu GH. Nursing research. Research on the cultivation of nursing master's degree from the perspective of professional embedded.J.17( 6),2054-2056(2014).

19. Zhang HL, Zhao QL, Zhang J. Chinese Journal of nursing. Current situation of the cultivation of master of nursing in nursing home and abroad.J.48( 6),571-573(2013).

20. Cui XY. Journal of Qilu Nursing. The feasibility and difficulties of the cultivation of nursing professional degree graduate students and training of specialized nurses.J.21(21),54-57(2015).

21. Li W.E ducation and Teaching Forum. To accelerate the promotion of professional degree education and professional qualification certification of organic convergence.J.( 51),1-2(2013). 